\title{
KAJIAN VISUAL BUKU OH! SI BURUNG HANTU DAN PENGARUHNYA TERHADAP PERKEMBANGAN MATA BAYI
}

\author{
Yunisa Fitri Andriani ${ }^{*}$, Yori Pusparani ${ }^{2}$ \\ ${ }^{1,2}$ Desain Komunikasi Visual, Fakultas Industri Kreatif Institute Teknologi dan Bisnis Kalbis \\ Diterima: 16 Agustus 2018/ Disetujui: 12 Oktober 2018
}

\begin{abstract}
Newborns cannot see clearly. The viewing distance is only around 20 to $30 \mathrm{~cm}$. In the first month of life, the baby's vision is still blurred and can only recognize the light, shape, and movement around it. He also has not been able to distinguish colors, other than achromatic like black and white. stepping on the age of 1 to 3 months, when babies begin to be able to distinguish colors, but babies cannot distinguish colors that are similar to red and orange. Despite being able to distinguish colors, babies are still more interested in black and white. The ability of the eyes of babies from birth to 3 months is still very limited, but adults around them can help stimulate these abilities to develop properly. The form of stimulation that can help the development of a baby's eye is to read the book. Oh! The Owl is a storybook intended for newborns and to help parents stimulate the development of the baby's eyes. This research was conducted to analyze the colors and simple patterns applied by the author of the book Oh! The Owl is suitable for baby's eyes which has limited vision in terms of color and distance. This research is a qualitative research with content analysis that maps color theory and visual language to illustrated story books Oh! The owl.
\end{abstract}

Keywords: baby eyes, baby story books, color theory, visual language, design.

\begin{abstract}
ABSTRAK
Bayi baru lahir belum dapat melihat dengan jelas. Jarak pandangnya hanya sekitar 20 hingga 30cm. Di 1 bulan awal hidupnya, pandangan bayi masih kabur dan hanya dapat mengenali cahaya, bentuk, serta gerakan di sekitarnya. Ia juga belum dapat membedakan warna, selain akromatik seperti hitam dan putih. Menginjak usia 1 hingga 3 bulan, ketika bayi mulai dapat membedakan warna, tetapi bayi belum dapat membedakan warna yang serupa seperti merah dan jingga. Meskipun sudah dapat membedakan warna, bayi masih lebih tertarik dengan hitam dan putih. Kemampuan mata bayi dari lahir hingga 3 bulan masih sangat terbatas, tapi orang dewasa di sekitarnya dapat membantu menstimulasi kemampuan tersebut agar berkembang dengan baik. Bentuk stimulasi yang dapat membantu perkembangan mata bayi adalah dengan membacakannya buku. Oh! Si Burung Hantu merupakan buku cerita yang diperuntukkan untuk bayi baru lahir dan untuk membantu para orang tua untuk menstimulasi perkembangan mata bayi. Penelitian ini dilakukan untuk menganalisa warna serta pola sederhana yang diaplikasikan sang penulis buku Oh! Si Burung Hantu apakah sesuai untuk mata bayi yang memiliki keterbatasan pandangan dari segi warna dan jarak. Penelitian ini adalah penelitian kualitatif dengan analisis konten yang memetakan teori warna dan bahasa rupa pada buku cerita bergambar Oh! Si Burung Hantu.
\end{abstract}

Kata kunci: mata bayi, buku cerita bayi, teori warna, bahasa rupa, perancangan.

\section{LATAR BELAKANG}

Sewaktu lahir, manusia belum memiliki kemampuan visual yang baik. Kemampuan mata yang manusia butuhkan dalam hidup merupakan sesuatu yang harus dipelajari. Sebagaimana manusia yang berusia lebih tua, bayi juga berinteraksi selain melalui verbal juga melalui visual.
Sejak lahir, secara fisik bayi sudah dapat melihat namun otaknya belum siap untuk memproses semua informasi visual itu. Usia bayi baru lahir hingga 3 bulan masih perlu belajar bagaimana menggunakan informasi visual yang dikirim mata ke otak mereka untuk

*email: yunisa.andriani@kalbis.ac.id 
memahami dunia di sekitar mereka dan berinteraksi dengannya.

Melalui mata, bayi mendapatkan informasi tentang dunia di sekitarnya yang berguna untuk perkembangan fisik, mental dan emosional mereka. Begitu pentingnya mata dalam perkembangan bayi, sehingga masalah mata dan penglihatan pada bayi bisa menyebabkan keterlambatan perkembangan.

Orang tua berperan penting dalam membantu memastikan mata dan pandangan anak mereka tidak memiliki masalah dan berkembang dengan baik. Salah satu bentuk tindakan orang tua dalam membantu perkembangan mata anak mereka adalah dengan membacakannya buku cerita. Buku cerita bayi dengan mempertimbangkan perkembangan mata bayi masih sangat jarang. Di pasaran sekarang ini, buku cerita yang diperuntukkan untuk bayi mayoritas memiliki banyak warna dan banyak bentuk visual di dalamnya. Berbeda dengan buku cerita yang ada di pasaran, buku Oh! Si Burung Hantu hanya memiliki warna hitam dan putih dan 1 warna kontras yaitu merah. Buku ini juga hanya memiliki bentuk visual sederhana seperti persegi, segitiga dan lingkaran.

Mengingat pentingnya perkembangan mata bayi dan keterbatasan pandangan yang dimiliki bayi maka pemilihan buku cerita untuk bayi menjadi sangatlah penting. Penelitian ini merumuskan beberapa masalah terkait latar belakang yang telah dijabarkan di atas, diantaranya adalah :

1. Bagaimanakah pengaruh warna pada buku Oh! Si Burung Hantu terhadap perkembangan mata bayi usia 0-3 bulan?

2. Bagaimanakah pengaruh visual pada buku Oh! Si Burung Hantu terhadap perkembangan mata bayi usia $0-3$ bulan?

Serta agar masalah di atas tetap fokus dalam penelitian ini maka masalah yang ada dibatasi pada perkembangan mata bayi usia 0-3 bulan, analisa buku Oh! Si Burung
Hantu, perancangan karya sejenis untuk bayi usia 0-3 bulan.

\section{TINJAUAN KEPUSTAKAAN \\ Buku "Oh! Si Burung Hantu"}

a. Profil Penulis

Buku "Oh! Si Burung Hantu"

ditulis oleh Clefiena lulusan

FSRD ITB angkatan 2002.

Clefiena adalah ibu rumah tangga sekaligus seniman kreatif dan desainer di Cleferik Creative. Selain menulis buku, Clefiena juga mendirikan self publishing buku edukatif anak bernama Cleferik Doodle Books. Self publishing ini bermula dari kegiatan homeschooling bermain sambil belajar melalui buku yang diciptakan oleh Clefiena sendiri untuk anak-anaknya, yang kemudian mendapatkan tanggapan positif dari follower Instagram Clefiena. Semua buku Cleferik Doodle Books merupakan buku edukatif dengan desain dan ilustrasi sederhana, unik dan menarik, dan telah terjual lebih dari 1000 eksemplar.

b. Profil Buku

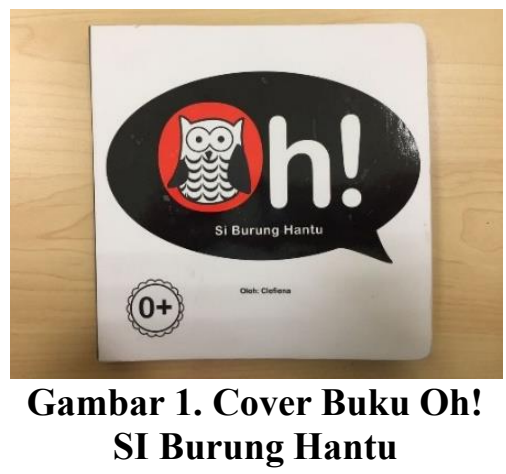

Buku "Oh! Si Burung Hantu" diperuntukkan untuk bayi usia 0-3 bulan. Buku ini merupakan buku berjenis boardbook atau buku yang dicetak di atas papaerboard. Bahannya tebal 
dan tidak mudah sobek sehingga cocok untuk target audience-nya. Berdasarkan target audience-nya juga, buku ini dedesain dengan pola sederhana dan warna kontras agar bayi mudah merespons konten isinya. Buku ini diharapkan dapat menstimulasi potensi visual bayi sejak dini, yang pada akhirnya akan mendorong perkembangan bayi secara keseluruhan.

\section{Perkembangan Mata Bayi}

Sejak lahir, bayi sudah dapat melihat, namun bayi belum memiliki semua kemampuan yang ia butuhkan dalam hidup. Semua kemampuan tersebut perlu dipelajari. Menurut American Optometric Association, Bayi belum dapat memfokuskan matanya kepada dua objek, objek yang jauh dan warna yang serupa. Jarak pandang mereka masih sebatas 20-30 $\mathrm{cm}$. Jarak tersebut cukup untuk mengenali wajah ibunya ketika memberikan ASI. Di usia ini, bayi sudah bisa melihat warna, namun belum bisa membedakan warna yang serupa, karena itu bayi lebih tertarik dengan warna kontras seperti hitam dan putih. Warna kontras dapat membuat mata bayi lebih fokus.

Sebelum belajar meraih benda, merangkak atau duduk bayi lebih dulu memperoleh informasi dari apa yang dilihatnya. Bayi belajar bagaimana mengeksplor dunia dan berinteraksi dengannya lewat penglihatannya.

Di dua bulan pertama kehidupan, bayi belum dapat menkoordinasi penglihatannya dengan baik. Bayi sudah harus mulai mengikuti benda yang bergerak dengan mata dan meraih benda yang ada di sekitarnya di usia tiga bulan.

Perkembangan bayi sangat dipengaruhi oleh perkembangan visualnya. Pentingnya peran mata dalam perkembangan bayi, maka stimulasi diperlukan untuk mengantisipasi keterlambatan perkembangan. Stimulasi yang baik dan tepat dapat membantu merangsang kemampuan mata bayi secara optimal.

\section{Teori Warna}

Akhir tahun 1600, Sir Isaac Newton melakukan sebuah percobaan dan menyimpulkan bahwa warna dihasilkan dari cahaya. Pada percobaan Newton, cahaya dipantulkan ke sebuah prisma kaca dan menghasilkan 7 warna individu, yaitu merah, jingga, kuning, hijau, biru, nila dan ungu. Cahaya terbuat dari gelombang elektromagnetik yang dihasilkan oleh sumber cahaya, seperti matahari, lampu dan lain sebagainya. Terdapat beberapa panjang gelombang yang berpengaruh terhadap warna yang kita lihat. Warna merah memiliki gelombang yang paling panjang dan warna ungu memiliki gelombang yang terpendek.

Newton juga menyimpulkan bahwa mata manusia memiliki berbagai penangkap/penerima cahaya (fotoreseptor) untuk menangkap berbagai jenis warna cahaya yang memantul dari sebuah benda.

Hal yang sama terjadi pada mata bayi, namun karena mata bayi belum berkembang sepenuhnya, mereka hanya dapat melihat merah, oranye, kuning dan hijau dan membutuhkan waktu sedikit lebih lama bagi bayi untuk dapat melihat warna biru dan ungu. Hal ini karena cahaya biru memiliki panjang gelombang yang lebih pendek, dan reseptor warna yang ada di dalam retina mata bayi masih sedikit untuk cahaya biru.

Monokrom menggambarkan lukisan, gambar, desain, atau foto dalam satu warna atau nilai dari satu warna. Benda monokromatik atau gambar mencerminkan warna dalam warna dan warna yang terbatas. Gambar yang hanya menggunakan nuansa abu-abu (dengan atau tanpa hitam atau putih) disebut grayscale atau hitamputih. Namun, secara ilmiah, cahaya monokromatik mengacu pada cahaya tampak dari pita sempit panjang gelombang. 


\section{Bahasa Rupa}

Bahasa Rupa adalah teori yang
menyatakan bahwa visual yang representatif dapat dirancang untuk menyampaikan pesan kepada pembacanya dengan struktur tertentu. Artinya sebuah visual dan bahkan sekuens visual dapat merupakan serangkaian informasi yang bukan sekedar menjelaskan apa yang tergambar secara deskriptif, tetapi juga dapat menceritakan informasi secara naratif. Visual yang dapat menceritakan informasi secara naratif ini dibagi dalam tiga struktur, yaitu:

\section{a. Wimba}

merupakan elemen terkecil yang mengandung pesan deskriptif yang paling sederhana dalam sebuah komposisi gambar. Teknik membentuk wimba ini disebut, cara wimba (image way).

b. Tata Ungkap Dalam adalah merupakan sekelompok wimba yang membentuk pesan naratif melalui komposisi yang dibentuknya.

c. Tata Ungkap Luar

adalah kumpulan sekelompok wimba yang membentuk beberapa komposisi yang berurutan.

\section{TUJUAN}

Buku cerita untuk bayi yang beredar di pasaran memiliki desain yang rumit dan warna yang banyak. Sangat jarang ditemui buku cerita bayi dengan warna hitam putih dan kontras serta visual yang sederhana, maka hasil analisa buku cerita $\mathrm{Oh} ! \mathrm{Si}$ Burung Hantu bertujuan untuk membantu keilmuan desain grafis dan ilustrasi buku anak dalam memproduksi buku dan karya yang baik untuk perkembangan visual bayi 0-3 bulan. Penelitian ini juga diharapkan dapat bermanfaat bagi peneliti dalam menambah pengetahuan tentang perkembangan mata bayi, dapat memahami dan merancang karya yang baik bagi perkembangan mata bayi, serta bermanfaat orang tua dalam memilih buku cerita yang baik bagi perkembangan mata bayi, membantu orang tua dalam menstimulasi perkembangan mata anak mereka, juga membantu perkembangan mata bayi dan perkembangan lainnya.

\section{METODE PENELITIAN \\ Objek Penelitian}

Penelitian ini difokuskan pada perkembangan mata bayi usia 0-3 bulan dan visual pada buku cerita yang diperuntukkan untuk bayi usia tersebut. Perkembangan mata bayi di usia 0-3 bulan sangat penting karena berpengaruh pada perkembangan lainnya. Sewaktu bayi belum bisa menggerakkan anggota badan lainnya dengan baik, bayi mengobservasi sekitarnya melalui mata. Pada penelitian ini akan dianalisa bagaimana visual yang baik bagi perkembangan mata bayi. Hal yang dapat dilakukan orang tua dalam membantu perkembangan mata bayi adalah dengan membacakannya cerita. Menurut survey, buku yang khusus didesain untuk bayi 0-3 bulan masih jarang di pasaran maka, studi kasus dipilih sebagai metode yang tepat untuk meneliti objek penelitian buku cerita bayi.

\section{Metode Pengumpulan Data}

Beberapa metode digunakan dalam penelitian ini untuk mendapatkan data yang lengkap, relevan dan akurat. Metode yang digunakan antara lain :

\section{Studi Pustaka}

Melalui metode studi pustaka, peneliti mengumpulkan data dan mempelajari teori Bahasa rupa dan teori warna yang menjadi dasar dalam menganalisa visual pada buku cerita bayi.

\section{Observasi}

Metode observasi digunakan dengan menggunakan 2 jenis buku cerita bayi yang dibacakan pada bayi usia 0-3 bulan. Jenis buku pertama adalah buku cerita bayi yang ada di pasaran dan yang kedua adalah buku Oh! Si Burung Hantu. Melalui metode ini peneliti dapat mengobservasi buku mana yang dapat membuat mata bayi lebih fokus. 


\section{HASIL DAN PEMBAHASAN}

Metode yang digunakan pada penelitian ini adalah metode kualitatif dan kuantitatif. Isi dari buku cerita $\mathrm{Oh}$ ! Si Burung Hantu akan dianalisa dengan menggunakan metode kualitatif melalui teori bahasa rupa dan teori warna.

Hal pertama yang akan dibahas adalah jumlah warna yang digunakan. Buku ini hanya menggunakan warna hitam dan putih dan 1 warna kontras yaitu merah.

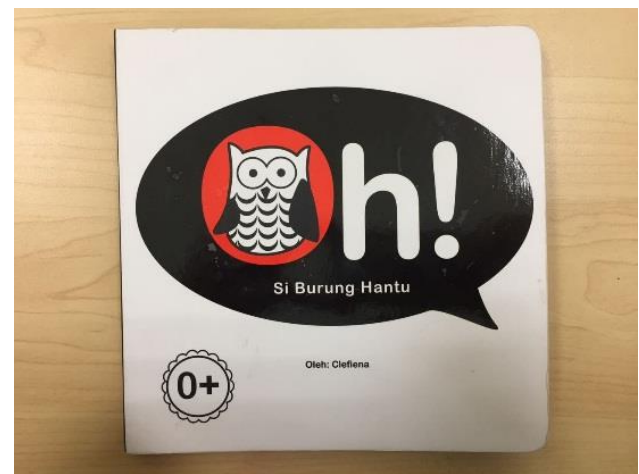

Gambar 2. Cover Buku Oh! SI Burung Hantu

Berdasarkan gambar di atas, cover buku cerita ini juga hanya memuat warna hitam putih dan merah.

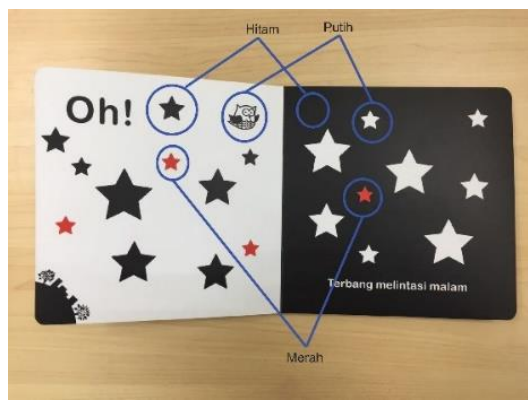

Gambar 3. Bagian isi

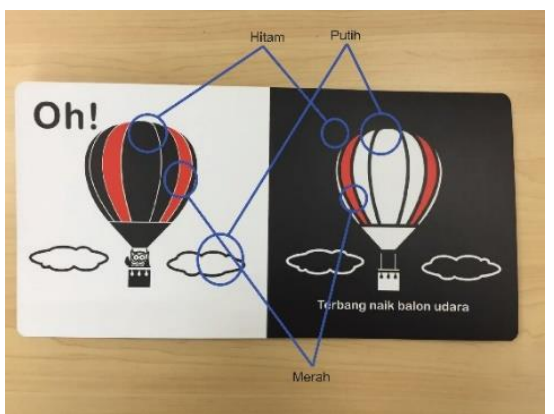

Gambar 4. Bagian isi
Dilihat dari 2 bagian isi buku cerita ini juga terlihat 3 warna dominan yang digunakan yaitu hitam, putih dan merah. Seperti yang telah dijelaskan di atas bahwa hitam dan putih dihasilkan dari gelap terang atau cahaya tampak dari pita sempit panjang gelombang sehingga hitam dan putih adalah sesuatu yang pertama dilihat bayi sebelum retinanya menangkap gelombang warna. Sedangkan warna merah adalah warna yang memiliki panjang gelombang paling panjang sehingga mudah ditangkap oleh retina mata bayi.

Berdasarkan elemen visual bentuk yang digunakan, buku Oh! Si Burung Hantu hanya menggunakan bentuk geometris sederhana. Bentuk-bentuk tersebut akan dianalisa secara kualitatif dengan teori bahasa rupa.

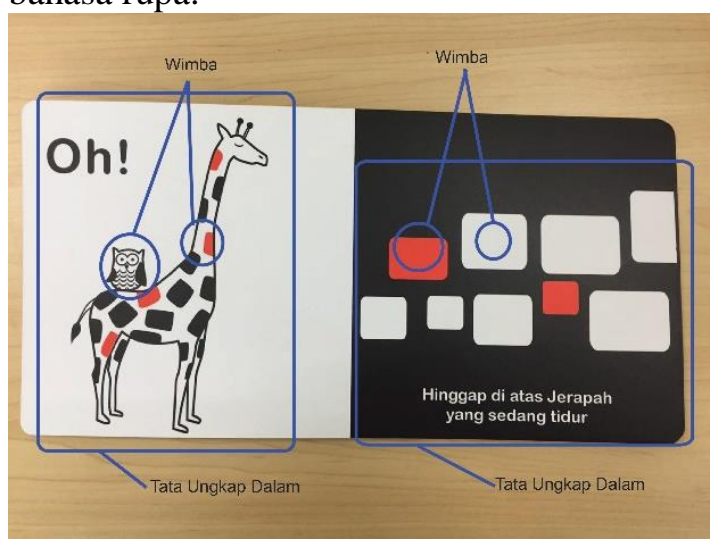

Gambar 5. Wimba dan Tata Ungkap Dalam

Berdasarkan gambar di atas dijelaskan bagian isi buku yang merupakan wimba dan tata ungkap dalam. Wimba di dalam buku ini menggunakan bentuk-bentuk sederhana membentuk suatu komposisi yang disebut sebagai tata ungkap dalam.

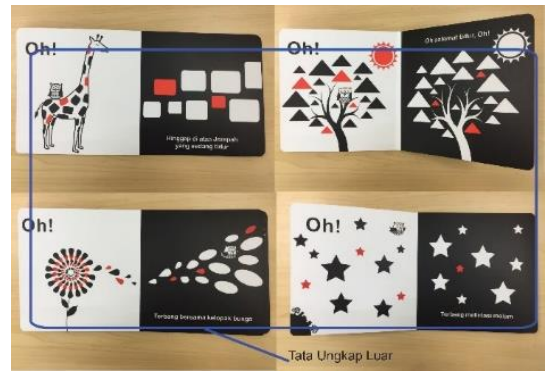

Gambar 6. Tata Ungkap Luar 
Dilihat dari gambar di atas dijelaskan bagian isi buku yang tersusun berurutan mencakup kumpulan wimba yang membentuk tata ungkap dalam dan tata ungkap dalam tersebut disusun berurutan membentuk tata ungkap luar. Berikutnya, buku Oh! Si Burung Hantu akan dianalisa menggunakan metode kuantitatif melalui survey langsung ke target audience yaitu bayi usia 0-3 bulan.
Survey ini telah dilakukan di baby daycare Daarul Quran, Jakarta Selatan pada 5 bayi usia 3 bulan, 2 bayi usia 2 bulan, 2 bayi usia 1 bulan dan 1 bayi baru lahir dengan memperlihatkan 2 buku yang berbeda. Buku pertama adalah beberapa buku bayi yang banyak ditemukan di toko buku. Beberapa diantara buku ini berjenis softbook, menggunakan banyak warna dan gambar yang rumit. Buku kedua adalah buku Oh! Si Burung Hantu.

\begin{tabular}{|c|c|c|c|c|}
\hline No. & Nama & $\begin{array}{c}\text { Usia } \\
\text { (bulan) }\end{array}$ & $\begin{array}{c}\text { Reaksi terhadap } \\
\text { buku 1 }\end{array}$ & $\begin{array}{c}\text { Reaksi terhadap } \\
\text { buku 2 }\end{array}$ \\
\hline 1. & Alby & 3 & Meraih buku & $\begin{array}{c}\text { Memperhatikan } \\
\text { gambar }\end{array}$ \\
\hline 2. & Bhyan & 3 & Diam & $\begin{array}{c}\text { Mata mengikuti } \\
\text { gambar }\end{array}$ \\
\hline 3. & Arfa & 3 & Mengoceh & $\begin{array}{c}\text { Memperhatikan } \\
\text { gambar }\end{array}$ \\
\hline 4. & Kenzie & 3 & Meraih buku & $\begin{array}{c}\text { Memperhatikan } \\
\text { gambar }\end{array}$ \\
\hline 5. & Arya & 3 & Diam & $\begin{array}{c}\text { Mata mengikuti } \\
\text { gambar }\end{array}$ \\
\hline 6. & Awan & 2 & Diam & $\begin{array}{c}\text { Mata mengikuti } \\
\text { gambar }\end{array}$ \\
\hline 7. & Naya & 2 & Mengoceh & $\begin{array}{c}\text { Mata mengikuti } \\
\text { gambar }\end{array}$ \\
\hline 8. & Gendis & 1 & Diam & $\begin{array}{c}\text { Memperhatikan } \\
\text { gambar }\end{array}$ \\
\hline 9. & Aqila & 1 & Diam & $\begin{array}{c}\text { Memperhatikan } \\
\text { gambar }\end{array}$ \\
\hline 10. & Sigi & 0 & Diam & Diam \\
\hline
\end{tabular}

Dilihat dari tabel di atas, mata bayi lebih fokus pada buku kedua yaitu buku Oh! Si Burung Hantu dan bayi kurang tertarik dan kurang fokus ketika melihat sekumpulan buku pertama.

\section{KESIMPULAN}

Pemilihan warna dalam buku Oh! Si Burung Hantu ini sesuai dengan teori warna oleh Isaac Newton. Hitam dan putih yang dihasilkan oleh cahaya sangat mudah ditangkap mata bayi sehingga bayi dapat lebih fokus pada objek yang ada di dalam buku tersebut. Berdasarkan hasil survey juga dapat ditarik kesimpulan bahwa mata bayi lebih fokus pada buku berwarna monokrom dan 1 warna kontras daripada buku dengan banyak warna.

Sedangkan menurut teori Bahasa rupa yang diungkapkan oleh Primadi Tabrani pada buku Bahasa Rupa, wimba dalam buku ini merupakan bentuk geometris sederhana seperti bintang, persegi, segitiga dan lingkaran. Jika dikaitkan dengan perkembangan mata bayi di usia 0-3 bulan, bentuk sederhana ini lebih mudah ditangkap oleh mata bayi yang hanya dapat menangkap objek berjarak 20$30 \mathrm{~cm}$. Berdasarkan hasil survey juga dapat ditarik kesimpulan bahwa mata bayi dapat mengikuti alur gambar pada tata ungkap buku Oh! Si Burung Hantu dari awal hingga akhir. 
Perbedaan yang signifikan pada hasil survey antara 2 jenis buku bayi, maka kesimpulannya adalah buku bayi dengan warna monokrom dan 1 warna kontras dan bentuk sederhana memberi pengaruh terhadap penglihatan bayi. Warna dan bentuk pada buku ini dapat menstimulasi mata bayi untuk lebih fokus dan bergerak mengikuti gambar.

\section{DAFTAR RUJUKAN}

Tabrani, Primadi; 2005; Bahasa Rupa; Penerbit Kelir, Bandung.

Mollica, Patti; 2013; Color Theory; Walter Foster Publishing, California.

Long, James Thomas; The New Munsell Student Color Set; Bloomsbury Publishing Inc, New York.
Caputo, Tony C.; 2003; Visual Storytelling, The Art \& Technique; Watson Guptill Publications; New York.

Lukman, Chritine. 2009; Bahasa Rupa pada Buku Ilustrasi Anak Indonesia Kontemporer; Studi Kasus Seri Cerita Pelangi Gramedia Pustaka Utama (GPU). Universitas Kristen Maranatha, Bandung.

Tabrani, Primadi. 2009. Wimba, Asal usul dan Peruntukannya. Institut Teknologi Bandung.

https://www.aoa.org/ https://hellosehat.com/ http://www.ayahbunda.co.id/ http://cleferikdoodle.com// 